\title{
Ethics Content In Strategic Management Textbooks: A Longitudinal Examination
}

\author{
Scott W. Geiger, University of South Florida St. Petersburg, USA
}

\begin{abstract}
The purpose of this study is to examine the prevalence of ethics content in strategic management textbooks. The importance of ethical behavior within organizations has been highlighted in the past by organizations, such as Enron and WorldCom, and more recently by British Petroleum and Toyota. The data collected from two different editions of five strategic management texts suggest that ethical content coverage has improved greatly over the past eight years. Implications for both authors and instructors are discussed.
\end{abstract}

Keywords: Ethics, Strategic Management, Textbooks

\section{INTRODUCTION}

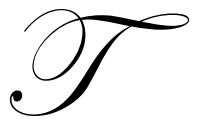

he management literature has recently given increased attention to the topic of business ethics (Jones, 1991; Robin, Reidenbach, \& Forrest, 1996; Street, Douglas, Geiger, \& Martinko, 2001, Piercy \& Lane, 2007). This attention has been mirrored in the popular press as high profile ethical breaches in corporate America continue to emerge. Indeed, over the past several years, some of the largest firms in the U.S. have suffered failure due to unethical behavior within top management. Given these incidents, the management literature continues to address the importance of moral conduct and to emphasize the need for a greater understanding of ethical decision-making (Piotrowski and Guyette, 2010).

The extent to which the above-mentioned unethical behaviors are pertinent to both the strategic management process, and ultimately firm performance, requires that the field of strategic management address this topic. Certainly the study of ethics within strategic management is not new. Prior research by Freeman (1984), later followed by Hosmer (1994) and Singer (1994), firmly planted the topic of ethics within the strategic management discipline. More recent work has further advanced the examination of ethics within strategy (Gilbert, 1995, 2001).

Also important within the field of strategic management is communication of the field's knowledge in the classroom. While a great deal of attention has been given to the topic of ethics among strategy scholars, little is known about the extent to which ethics content is being taught at the undergraduate and MBA level. Thus, as a field, we may be failing our students with critical content necessary for success in the market place.

The purpose of this study is to examine the prevalence of ethics content in strategic management courses. To do so, the ethics content within strategy texts will be measured and analyzed. To date, no known studies have examined the extent to which ethics is included in strategic management texts. Examining this issue is critical for advancing the field and preparing students with the necessary knowledge base for success in their careers.

In the paragraphs that follow, a history of the strategic management course will be presented and the relationship between strategy and ethics will be discussed. Next, the methodological procedures will be described. Finally, the results will be presented and the implications and limitations of the findings will be discussed.

\section{The Strategic Management Course}

The origins of strategic management date back to 1912 at the Harvard Business School where the first business policy course was offered (Cruikshank, 1987). Historically, business policy/strategic management courses have been offered as an integrative review within the business curriculum (Kesner, 2001). As such, strategic 
management was taught as a capstone course by faculty from diverse disciplines, such as economics, marketing and accounting. During the early years of business policy courses, the typical pedagogy involved the case method of teaching.

However, as the strategic management field developed in the 1970s and 1980s, a greater focus was put on strategy as a separate field. Furthermore, the creation of doctoral programs in strategic management resulted in faculty specifically trained to teach strategy and conduct research on the subject (Kesner, 2001). As such, strategy is now commonly taught by faculty with doctoral training in strategic management. Also, the coverage of content and methods of teaching now vary greatly. For example, in contrast to the exclusive use of the case method, instructors incorporate other methods, such as traditional lecture, computer simulation games, and experiential exercises.

As noted by Greiner, Bhambri, and Cummings (2003) in a study of top MBA programs, strategy no longer serves as the capstone course at the dominant majority of elite schools. Further, almost all the schools in this study moved from emphasizing practice to theory and analytics. Currently, the strategy course is no longer needed for meeting AACSB standards. However, it is firmly planted as a core course at both the undergraduate and graduate levels (Kesner, 2001).

In his review of corporate strategy and ethics, Gilbert (2001) discusses the relationship between the strategic management process and ethics. It is argued by Gilbert that ethics has often been treated as a modifying variable within the strategic management process. As evidence of this, Gilbert notes that most strategic management texts treat ethics as a modifying influence on the strategic management process. As such, a link between ethics and the strategic management process has been firmly established in the textbook literature. However, Gilbert (2001) argues that while strategy texts have treated ethics as a modifier of the strategic management process, recent research suggests ethics does more than just modify the process. Specifically, research by Hosmer (1994) and Singer (1994) suggests the strategic management process is an application of ethical reasoning (Gilbert, 2001). In the paragraphs that follow, the state of current texts will be examined to determine their treatment of ethics.

\section{METHODOLOGY}

\section{Sample}

To examine ethics content within strategy texts, a sample of five strategic management texts was selected from several publishers. Editions from the 2002-2003 and 2010-2011 time frame were utilized to capture the potential of change in ethics content. The texts matured in the range of three to four editions, depending on the text. For example, David (2003) was the $9^{\text {th }}$ edition while David (2011) was the $13^{\text {th }}$ edition. Included in this sample were books ranging from the $2^{\text {nd }}$ edition to $17^{\text {th }}$ edition. Given the nature of textbook publishing, books in their second edition and beyond typically retain a great deal of the market share. Both newer and mature books were included to prevent any bias of newness or oldness occurring in the results. The books selected in the sample can be seen in Table 1.

Table 1: Strategy Texts

\begin{tabular}{|c|c|c|}
\hline Author & $\begin{array}{c}\text { Title } \\
\end{array}$ & Publisher \\
\hline David (2003) & Strategic Management Concepts and Cases $9^{\text {th }}$ Edition & Prentice Hall \\
\hline David (2011) & Strategic Management Concepts and Cases $13^{\text {th }}$ Edition & Prentice Hall \\
\hline Harrison \& St. John (2002) & Foundations in Strategic Management $2^{\text {nd }}$ Edition & Thomson South-Western \\
\hline Harrison \& St. John (2010) & Foundations in Strategic Management $5^{\text {th }}$ Edition & Thomson South-Western \\
\hline Hitt, Ireland, \& Hoskisson (2003) & $\begin{array}{l}\text { Strategic Management Competitiveness and Globalization } \\
\text { Concepts and Cases } 5^{\text {th }} \text { Edition }\end{array}$ & Thomson South-Western \\
\hline Hitt, Ireland, \& Hoskisson (2011) & $\begin{array}{l}\text { Strategic Management Competitiveness and Globalization } \\
\text { Concepts and Cases } 9^{\text {th }} \text { Edition }\end{array}$ & Thomson South-Western \\
\hline Thompson \& Strickland (2003) & Strategic Management Concepts and Cases $13^{\text {th }}$ Edition & McGraw-Hill Irwin \\
\hline $\begin{array}{l}\text { Thompson, Strickland, } \\
\text { \& Gamble (2010) }\end{array}$ & $\begin{array}{l}\text { Crafting and Executing Strategy The Quest for Competitive } \\
\text { Advantage Concepts and Cases } 17^{\text {th }} \text { Edition }\end{array}$ & McGraw-Hill Irwin \\
\hline Wheelen \& Hunger (2003) & Strategic Management and Business Policy $9^{\text {th }}$ Edition & Prentice Hall \\
\hline Wheelen \& Hunger (2010) & Strategic Management and Business Policy $12^{\text {th }}$ Edition & Prentice Hall \\
\hline
\end{tabular}




\section{Data Collection}

To gather information on ethics content, each text in the sample was content analyzed. It is important to note that many strategy texts include both chapters and cases in one bounded text. In this study, only chapter content was analyzed. This was done for several important reasons. First, cases typically represent information relevant to specific organizations or industries. Second, most texts carry upwards of 30 cases and selection by professors varies. Typically, a professor utilizing the case method of teaching may cover approximately ten cases throughout the semester. Moreover, those using strategy simulations may use less of this approach. As such, much of the case material included in strategy texts goes uncovered by professors. Lastly, cases are typically not topic specific and include a broad range of issues, such as strategic missions, objectives, acquisitions strategies, financial statements, and culture, to name a few. This presents difficulties in content analyzing in that ethical issues could be embedded within a case without any specific mention of ethics or morality.

To content analyze the texts, a review of each chapter was conducted searching for material dealing with business ethics. As such, any content pertaining to business ethics, such as definitions, discussions of ethical models, codes of conduct, etc., were documented. It is important to note that some strategy texts link ethics and social responsibility, and indeed some refer to them as one in the same. For example, Harrison and St. John (2002) suggest that social responsibility is embedded within the application of ethics, while Thompson, Stickland, and Gamble (2010) include employing an ethical strategy as a component of social responsibility. Given this, content related to social responsibility is included within the data. While the inclusion of content related to social responsibility is debatable, it is done so for two important reasons. First, some strategy texts treat the content as linked or one in the same and second, results including ethics content and social responsibility content will provide the most liberal results.

The data collected for each text included the total number of pages, the number of pages including ethics content, the number of chapters including ethics content, the average number of pages per chapter, and the percentage of text pages involving ethics content. In addition, ethics content was categorized to determine the type of ethics content included in strategy texts. While no particular type of content was sought, examples of type of content include ethical decision-making models, codes of ethics, and ethical culture and leadership.

\section{RESULTS}

Results of the analyses appear in Tables 2, 3 and 4. For the 2002-2003 editions, the findings revealed that, on average, seven pages included ethics content per strategy text. The average text for these years included 339.2 pages in total. As such, $2.34 \%$ of pages within the 2002-2003 strategy texts involved ethics coverage. The range among texts was moderate with the lowest providing ethics content in five pages, while the text with the greatest ethics coverage involved 11 pages with ethics content.

Also of importance is the breadth of ethics coverage in strategy texts. To examine this, the number of chapters within each text was tabulated. The extent to which texts examine ethics in multiple chapters suggests numerous contexts within which the subject is discussed. On average 2.80 chapters included coverage of ethics material in the 2002-2003 texts. The lowest number of chapters within the sample providing ethics content was one and the highest number of chapters was five.

Table 2: Ethics Content in Strategy Texts (2002-2003)

\begin{tabular}{|l|c|c|c|c|c|}
\hline \multicolumn{1}{|c|}{ Author } & $\begin{array}{c}\text { Total \# } \\
\text { Pages }\end{array}$ & $\begin{array}{c}\text { Average } \\
\text { Pages Per } \\
\text { Chapter }\end{array}$ & $\begin{array}{c}\text { Total \# Pages } \\
\text { Including Ethics } \\
\text { Coverage }\end{array}$ & $\begin{array}{c}\text { Percentage of } \\
\text { Pages Including } \\
\text { Ethics Coverage }\end{array}$ & $\begin{array}{c}\text { \# Chapters } \\
\text { including Ethics } \\
\text { Coverage }\end{array}$ \\
\hline David (2003) & 321 & 35.67 & 5 & $1.56 \%$ & 2 \\
\hline Harrison \& St. John (2002) & 150 & 18.75 & 5 & $3.33 \%$ & 3 \\
\hline Hitt, Ireland, \& Hosskisson (2003) & 436 & 33.54 & 11 & $2.52 \%$ & 3 \\
\hline Thompson \& Strickland (2003) & 450 & 34.62 & 10 & $2.20 \%$ & 5 \\
\hline Wheelen \& Hunger (2003) & 339 & 23.21 & 7 & $2.06 \%$ & 1 \\
\hline Mean & 339.2 & 29.36 & 7.6 & $2.34 \%$ & 2.80 \\
\hline
\end{tabular}


For the 2010-2011 editions, the findings revealed that, on average, 17.6 pages included ethics content per strategy text. The average text for these years included 339 pages in total. As such, for the recent strategy texts $5.33 \%$ of pages involved ethics coverage. The range among texts was large for the 2010-2011 editions with the lowest coverage consisting of only seven pages of ethics content, while the text with the greatest coverage involved 37 pages containing ethics content. On average, three chapters included coverage of ethics material in the 2010-2011 texts. The lowest number of chapters within the sample providing ethics content was one and the highest number of chapters was six.

Table 3: Ethics Content in Strategy Texts (2010-2011)

\begin{tabular}{|l|c|c|c|c|c|}
\hline \multicolumn{1}{|c|}{ Author } & $\begin{array}{c}\text { Total \# } \\
\text { Pages }\end{array}$ & $\begin{array}{c}\text { Average } \\
\text { Pages Per } \\
\text { Chapter }\end{array}$ & $\begin{array}{c}\text { Total \# Pages } \\
\text { Including Ethics } \\
\text { Coverage }\end{array}$ & $\begin{array}{c}\text { Percentage of } \\
\text { Pages Including } \\
\text { Ethics Coverage }\end{array}$ & $\begin{array}{c}\text { \# Chapters } \\
\text { including Ethics } \\
\text { Coverage }\end{array}$ \\
\hline David (2011) & 344 & 31.27 & 17 & $4.94 \%$ & 2 \\
\hline Harrison \& St. John (2010) & 175 & 21.88 & 12 & $6.86 \%$ & 2 \\
\hline Hitt, Ireland, \& Hosskisson (2011) & 402 & 30.92 & 7 & $1.74 \%$ & 4 \\
\hline $\begin{array}{l}\text { Thompson, Strickland, \& Gamble } \\
\text { (2010) }\end{array}$ & 413 & 34.42 & 37 & $8.96 \%$ & 6 \\
\hline Wheelen \& Hunger (2010) & 361 & 30.08 & 15 & $4.16 \%$ & \\
\hline Mean & 339 & 29.71 & 17.6 & $5.33 \%$ & 1 \\
\hline
\end{tabular}

Table 4 provides a breakdown of topic coverage in the texts. A major focus within strategy texts is in the area of codes of ethics. All five texts in both editions had coverage in this area. For example, Wheelen and Hunger (2003) discuss the merits of codes of ethics and the results of research in this area. Moreover, Thompson et al. (2010) discuss the use of codes of ethics in developing an ethical culture.

Another theme covered by many of the texts was corporate social responsibility. For example, Wheelen and Hunger (2003) provide a discussion on the impact of the internet on governance and social responsibility, while Harrison and St. John (2002) include a section titled Ethics and Social Responsibility. Moreover, Thompson et al. (2010) devote nearly half a chapter to the topic of social responsibility and environmental sustainability.

Ethics, as pertaining to culture and leadership, was also covered in most texts. For example, under a topic heading of Emphasizing Ethical Practices, Hitt, Ireland and Hoskisson (2003) argue that to guide employee judgment and actions, ethical practices must influence the strategic management process and become an integral part of the culture. They further include a section discussing the cost of unethical decisions by strategic leaders.

The area most lacking in the texts was ethical theory and decision-making models. Only one text provided such coverage in the 2002-2003 timeframe. However, in the 2010-2011 timeframe, two texts provided extensive coverage of the topic.

Table 4: Frequency of Areas of Content for 2010-2011 Editions

\begin{tabular}{|l|c|}
\hline \multicolumn{1}{|c|}{ Areas of Ethics Content } & Number of Texts Including Area of Content \\
\hline Codes of Ethics & 5 \\
\hline Corporate Social Responsibility & 5 \\
\hline Culture and Leadership & 4 \\
\hline Ethical Reasoning and Decision-Making & 2 \\
\hline
\end{tabular}

\section{DISCUSSION}

Research examining the content of strategy texts has been lacking in the strategic management literature. Specifically, no known studies have examined the amount or type of ethics content contained within strategic management texts. In response to this gap in the literature, the current study examined the prevalence of ethics material in a sample of strategy texts over a multi-year period. By examining ethics in strategy texts, it is hoped that 
the strategy field can learn where it stands with regard to coverage of this important topic. This allows future strategy textbook authors the opportunity to consider what is currently being offered and perhaps make content decisions based on these finding or those of other future studies.

The findings of this study indicate that in the early 2000s, strategy texts, on average, offered minimal ethics content. However, the extent of ethics content has more than doubled and thus, has improved greatly since that time. Moreover, breadth of content, as measured by the number of chapters including ethics content, was low in the early 2000s and has improved slightly since. Specific topics receiving the greatest attention included codes of ethics, social responsibility, ethics in culture and leadership, and ethical reasoning and decision-making. Based on the above findings, it would appear that recent strategy texts treat ethics as more than just a modifying variable and indeed include it as a factor that goes into the strategy making process.

The results of this study suggest that the strategy field should consider the importance of ethics in strategic management. The extent to which business policy/strategic management is taught as a capstone integrative course suggests that greater ethics coverage would be warranted. If strategic management is taught as a differentiated discipline, the level of ethics content should also be considered given the need for ethical considerations in strategic decision-making.

Several implications arise from the findings of this study. First, the ethical decision-making literature suggests that more cognitive effort by individuals facing ethical issues results in a greater probability of ethical behavior (Street et al., 2001). Two factors involved in this cognitive effort are the motivation and ability of individuals. Ethics education should certainly impact ones ability to cognitively address a moral issue. As such, ethics education may help students to be better prepared when facing ethical dilemmas in the future. It appears that over the past eight years, strategy texts have improved significantly in the amount of ethics coverage integrated into the strategic management concepts. Moreover, it appears that more texts are now covering the topic of ethical theory and decision-making.

The results of this study also bring into question what type of ethics content should be covered in strategy texts. An argument can clearly be made that strategy texts should include coverage of codes of ethics. Also, coverage of the link between ethics and culture/leadership can certainly be justified. A more debatable topic within texts is that of social responsibility, but it appears there is a consensus among authors that the topic belongs in strategy courses. Moreover, should strategy texts include models of ethical reasoning or decision-making? This area of focus appears to be receiving more attention and seems warranted if students are to receive training on this topic. Recent editions, such as Thompson et al. (2010) and Wheelen and Hunger (2010), include extensive coverage of ethical reasoning models. While strategy texts vary in content, topics such as external analysis, competitive analysis, competitive and corporate level strategy, structure, and culture, are provided in all strategy texts. This suggests a general agreement within the field that this topic coverage is necessary. It is hoped that this study will serve as a step toward determining if or what type of ethics content should be included in strategy texts.

Like most research efforts, the current study does have limitations associated with it that provide opportunities for future research efforts. For example, the measurement of ethics provides objective measures of content within texts. However, it fails to capture the true extent to which professors integrate ethics into strategy courses. Thus, future research may benefit from studies measuring professors' use of ethics content outside that included in the text. Moreover, alternative measures of ethics content, such as case studies, would be useful in future studies.

It may also be beneficial for future researchers to examine some issues not investigated in the current study. For example, coverage of Sarbanes-Oxley and the implications toward governance should be of interest to students. Indeed, knowledge of this legislation should be of particular interest to those pursuing graduate education in business. Thus, studies examining the coverage of other important topics in strategy texts could prove valuable for both editors and authors.

Overall, it is hoped that this study will provide the strategy field with a greater understanding of ethics content in strategy texts. It is in the field's best interest to develop texts that enhance our understanding of factors 
impacting the strategic management process. Given the current business environment, ethics is clearly an important factor. It is hoped that this study will provide strategy instructors insight when choosing course material.

\section{AUTHOR INFORMATION}

Scott W. Geiger is an Associate Professor of Management at the University of South Florida St. Petersburg. His research has been published in journals such as Organizational Behavior and Human Decision Processes, Organizational Research Methods, the Journal of Business Ethics, and the Journal of Business Research.

\section{REFERENCES}

1. Cruikshannk, J. (1987). A Delicate Experiment: The Harvard Business School, 1908-1945. Boston, MA : Harvard Business School Press.

2. Eaton, R. F. and Sleigh, M. J. (2002). The Need for Comparative Research in Developmental Textbooks : A Review and Evaluation. Teaching of Psychology, 29, 101-105.

3. Freeman, R. E. (1984). Strategic Management : A Stakeholder Approach. Boston : Pitman.

4. Giltert, D. R., Jr. (1995). Management and Four Stakeholder Politics : Corporate Reengineering as a Crossroads Case. Business and Society, 34, 90-7.

5. Gilbert, D. R., Jr. (2001). Corporate Strategy an d Ethics, as Corporate Strategy Comes of Age. In M. A. Hitt, R. E. Freeman, \& J. S. Harrison (eds.). The Blackwell Handbook of Strategic Management (564-582). Oxford : Blackwell.

6. Greiner, L. E., Bhambri, A. and Cummings, T. G. (2003). Searching for a Strategy to Teach Strategy. Academy of Management Learning and Education, 2, 402-420.

7. Hosmer, L. (1994). Strategic Planning as if Ethics Mattered. Strategic Management Journal, 15, 17-34.

8. Jones, T. M. (1991). Ethical Decision Making by Individuals in Organizations: An Issue Contingent Model. Academy Of Management Review, 16(2), 366-395.

9. Kesner, I. F. (2001). The Strategic Management Course: Tools and Techniques for Successful Teaching. In M. A. Hitt, R. E. Freeman, \& J. S. Harrison (eds.). The Blackwell Handbook of Strategic Management (564-582). Oxford : Blackwell.

10. Piercy, N. and Nikala, L. (2007). Ethical and Moral Dilemmas Associated with Strategic Relationships between Business-to-Business Buyers and Sellers. Journal of Business Ethics, 72, 87-102.

11. Piotrowski, C. and Guyette, R.W. (2010). Toyota Recall Crisis: Public Attitudes on Leadership Ethics. Organization Development Journal, 28, 89-97.

12. Robin, D. P., Reidenbach, R. E., and Forrest, P. J. (1996). The Perceived Importance of an Ethical Issue as an Influence on the Ethical Decision-Making of Ad Managers. Journal of Business Research, 35, 17-28.

13. Singer, A. F. (1994). Strategy as a Moral Philosophy. Strategic Management Journal, 15, 191-213.

14. Street, M. D., Douglas, S., Geiger, S.W., \& Martinko, M. (2001). The Impact of Cognitive Expenditure on the Ethical Decision Making Process: An Integrated Model. Organizational Behavior and Human Decision Process, 86, 256-277. 